\title{
THE RELATIONSHIP BETWEEN THE FOURTH EDITION (2003) OF THE LOCUS OF CONTROL INVENTORY AND THE SIXTEEN PERSONALITY FACTOR QUESTIONNAIRE (VERSION 5)
}

\author{
JOHANN M SCHEPERS \\ abo@rau.ac.za \\ CLAIRE F HASSETT \\ Department of Human Resource Management \\ University of Johannesburg
}

\begin{abstract}
The principal objective of the study was to determine the relationship between the fourth edition (2003) of the Locus of Control Inventory (LCI) and version 5 of the Sixteen Personality Factor Questionnaire (16PF). After some minor changes the LCI was applied jointly with the 16PF to a sample of 3089 first-year university students. Complete records were obtained in respect of 3033 participants for the LCI, and 2798 for both the 16PF and the LCI. An iterative principal factor analysis of the LCI was done. The three-factor-structure previously found was substantiated by the analysis. Highly acceptable reliabilities were obtained. The $16 \mathrm{PF}$ yielded six global factors with reliabilities that ranged from 0,721 to 0,861 . Canonical correlations of 0,$659 ; 0,455$ and 0,322 were obtained between the three scales of the LCI and the primary factors of the $16 \mathrm{PF}$.
\end{abstract}

Key words

Locus of Control, Factor Structure, Sixteen Personality Factor Questionnaire

The third edition (1999) of the Locus of Control Inventory (LCI) produced very promising results indeed. In particular very interesting relationships with the Bar-On Emotional Quotient Inventory (Bar-On, 1997), the Sense of Coherence Scale (Antonovsky, 1993), and the Personal Orientation Inventory (Bloxom, 1972 \& Knapp, 1976) were found. However, certain minor changes of the LCI proved necessary. Furthermore it was deemed desirable to determine the relationship between the LCI and the Sixteen Personality Factor Questionnaire (16PF) as the 16PF is one of the most often used instruments in South Africa.

\section{Statement of the problem}

The principal objective of the study was to determine the relationship between the LCI and the 16PF, but in order to achieve this objective the following subsidiary goals had to be met first:

- The factor-structure and metrical properties of the LCI had to be determined, and

- the factor structure and metrical properties of the $16 \mathrm{PF}$ (Version 5) had to be determined.

\section{RESEARCH DESIGN}

Research approach

Logically the study falls into two sections. The first section deals with the factor structure and metrical properties of the LCI and the $16 \mathrm{PF}$, and the second section with the relationship between the two instruments. Section 1 will be dealt with first and then Section 2 .

The planned study is quantitative in nature. Principal factor analysis and item analysis will be used in Section 1 of the study. In Section 2 a canonical correlation analysis will be done. The data will be collected by means of a cross-sectional field study.

\section{THE FACTOR STRUCTURE AND METRICAL PROPERTIES OF THE LCI}

\begin{abstract}
Sample
The full complement of first-year university students at the Rand Afrikaans University was tested with the LCI and 16PF during 2003. All incomplete records were rejected. The final sample consisted of 3089 participants in respect of the 16PF and 3033 in respect of the LCI. For the sake of brevity only the bigger sample will be described here.

The sample was representative of all the faculties of the university. The ages of the students ranged from 17 to 43 years with a mean of 19,30 years and a standard deviation of 1,662 years. The various cultural groups were represented as follows: Blacks 17,8\%; Coloureds 4,3\%; Indians $6,2 \%$ and Whites $68,5 \%$. As far as gender is concerned $41,5 \%$ of the sample were male and $55,3 \%$ were female. As far as language is concerned $42,6 \%$ of the sample spoke English, $26,2 \%$ of the sample spoke Afrikaans and 9,5\% were fluent in both English and Afrikaans. Only $5,6 \%$ of the sample indicated an African language as their home language. Missing information accounted for 3,2\% of the sample.
\end{abstract}

\section{Measuring instrument}

From the statistical analysis of the third edition (1999) of the LCI it became clear that items 11 and 17 should be included in the category of Internal Control rather than External Control and that item 11 should be reflected. Furthermore, it was clear that items 26, 62 and 78 should be revised. All these changes were made in the fourth edition (2003) of the LCI.

As the procedure that was followed in the analysis of the LCI has been fully described by Schepers (2004) only the essential results are given here. 


\section{RESULTS}

The items of the LCI were intercorrelated and the eigenvalues of the unreduced intercorrelation matrix were calculated. These matrices, however, are too big for reproduction here. $\left.{ }^{1}\right)$ Nineteen of the eigenvalues were greater than unity, accordingly 19 factors were extracted and rotated to simple structure by means of a Varimax rotation (Kaiser, 1961).

Next, 19 subscores were formed by adding all the items with substantial loadings on a factor, together. The 19 subscores were then intercorrelated, and the matrix of intercorrelations is given in Table 1.

Table 1 shows that the correlations of the subscores with one another vary from moderate to low and from positive to negative, suggesting several factors.

Next, the eigenvalues of the unreduced intercorrelation matrix $(19 \times 19)$ were calculated. The obtained eigenvalues are given in Table 2.
Table 2 shows that four of the eigenvalues are greater than unity, suggesting four factors (Kaiser, 1961). Accordingly four factors were extracted and rotated to simple structure by means of a Direct Oblimin rotation.

The rotated factor matrix yielded three well determined factors and a fourth factor with only two loadings that were very low. It was therefore decided to extract only three factors.

The rotated three-factor-solution is given in Table 3.

From Table 3 it is evident that all three factors are well determined with five or more high loadings. Twenty-eight items relating to Autonomy had substantial loadings on Factor I. Accordingly Factor I was interpreted as Autonomy. Twenty-nine items associated with External Control had substantial loadings on Factor II. Factor II was therefore interpreted as External Control. Thirty-one items relating to Internal Control had substantial loadings on Factor III. Factor III was therefore interpreted as Internal Control.

TABLE 1

MATRIX OF THE INTERCORRELATIONS OF THE SUBTESTS OF THE LOCUS OF CONTROL INVENTORY (2003)

\begin{tabular}{|c|c|c|c|c|c|c|c|c|c|}
\hline Variable & Subtest 1 & Subtest 2 & Subtest 3 & Subtest 4 & Subtest 5 & Subtest 6 & Subtest 7 & Subtest 8 & Subtest 9 \\
\hline Subtest 1 & 1,000 & & & & & & & & \\
\hline Subtest 2 & 0,433 & 1,000 & & & & & & & \\
\hline Subtest 3 & $-0,099$ & $-0,147$ & 1,000 & & & & & & \\
\hline Subtest 4 & $-0,166$ & $-0,229$ & 0,438 & 1,000 & & & & & \\
\hline Subtest 5 & 0,378 & 0,496 & $-0,046$ & 0,101 & 1,000 & & & & \\
\hline Subtest 6 & $-0,218$ & $-0,272$ & 0,321 & $-0,482$ & $-0,151$ & 1,000 & & & \\
\hline Subtest 7 & 0,373 & 0,342 & $-0,108$ & $-0,220$ & 0,223 & $-0,172$ & 1,000 & & \\
\hline Subtest 8 & 0,440 & 0,578 & $-0,175$ & $-0,206$ & 0,420 & $-0,368$ & 0,262 & 1,000 & \\
\hline Subtest 9 & 0,436 & 0,175 & 0,045 & 0,111 & 0,240 & $-0,025$ & 0,136 & 0,183 & 1,000 \\
\hline Subtest 10 & 0,299 & 0,467 & $-0,110$ & $-0,156$ & 0,481 & $-0,193$ & 0,162 & 0,384 & 0,200 \\
\hline Subtest 11 & $-0,092$ & $-0,322$ & 0,318 & 0,450 & $-0,223$ & 0,449 & $-0,130$ & $-0,334$ & 0,073 \\
\hline Subtest 12 & 0,506 & 0,358 & $-0,077$ & $-0,150$ & 0,288 & $-0,156$ & 0,277 & 0,267 & 0,238 \\
\hline Subtest 13 & 0,334 & 0,185 & $-0,039$ & $-0,019$ & 0,126 & $-0,048$ & 0,126 & 0,212 & 0,191 \\
\hline Subtest 14 & $-0,118$ & $-0,189$ & 0,132 & 0,319 & $-0,083$ & 0,216 & 0,129 & $-0,152$ & 0,016 \\
\hline Subtest 15 & 0,157 & 0,285 & $-0,330$ & $-0,404$ & 0,140 & $-0,453$ & $-0,169$ & 0,275 & $-0,039$ \\
\hline Subtest 16 & 0,341 & 0,379 & $-0,143$ & $-0,238$ & 0,261 & $-0,252$ & 0,281 & 0,343 & 0,127 \\
\hline Subtest 17 & 0,125 & 0,275 & 0,030 & $-0,063$ & 0,207 & $-0,103$ & 0,117 & 0,229 & 0,095 \\
\hline Subtest 18 & 0,102 & 0,137 & 0,018 & $-0,023$ & 0,164 & $-0,047$ & 0,052 & 0,128 & 0,071 \\
\hline Subtest 19 & 0,367 & 0,308 & $-0,039$ & $-0,054$ & 0,283 & $-0,110$ & 0,194 & 0,307 & 0,225 \\
\hline \multicolumn{10}{|c|}{ Note. $\mathrm{N}=3033$} \\
\hline
\end{tabular}

Subtest 1

Subtest 2

Subtest 3

Subtest 4

Subtest 5

Subtest 6

Subtest 7

Subtest 8

Subtest 9

Subtest $10 \quad 1,000$

Subtest $11 \quad-0,260 \quad 1,000$

Subtest $12 \quad 0,245 \quad-0,095 \quad 1,000$

Subtest $13 \quad 0,158 \quad 0,028 \quad 0,181$

$\begin{array}{llll}\text { Subtest } 14 & -0,087 & 0,169 & -0,050\end{array}$

$\begin{array}{llll}\text { Subtest } 15 & 0,207 & -0,373 & 0,126\end{array}$

$\begin{array}{llll}\text { Subtest } 16 & 0,257 & -0,173 & 0,217\end{array}$

$\begin{array}{llll}\text { Subtest } 17 & 0,219 & -0,111 & 0,167\end{array}$

$\begin{array}{llll}\text { Subtest } 18 & 0,067 & -0,066 & 0,057\end{array}$

0,223

1,000

$-0,056 \quad 1,000$

$0,064 \quad-0,201$

$0,199 \quad-0,168$

$0,020 \quad-0,027$

$0,047 \quad 0,030$

1,000
0,215
0,035
0,059
0,086

1,000

0,086

0,077

1,000

0,177

$-0,106 \quad 0,086$

$0,149 \quad 0,064$ 
TABLE 2

EIGENVALUES OF UNREDUCED INTERCORRELATION MATRIX $(19 \times 19)$

\begin{tabular}{lc}
\hline Root & Eigenvalue \\
\hline 1 & 4,802 \\
2 & 2,252 \\
3 & 1,249 \\
4 & $\mathbf{1 , 0 0 2}$ \\
5 & 0,938 \\
6 & 0,918 \\
7 & 0,866 \\
8 & 0,824 \\
9 & 0,760 \\
10 & 0,729 \\
11 & 0,691 \\
12 & 0,650 \\
13 & 0,610 \\
14 & 0,586 \\
15 & 0,496 \\
16 & 0,481 \\
17 & 0,422 \\
18 & 0,383 \\
19 & 0,343 \\
\hline Trace & 19,000 \\
\hline
\end{tabular}

From the intercorrelations of the factors given in Table 3 it is clear that External Control and Internal Control are essentially uncorrelated. Internal Control is substantially $(r=0,521$; $\mathrm{p}<0,001)$ correlated with Autonomy, and External Control is moderately negatively correlated with Autonomy $(r=-0,324$; $\mathrm{p}<0,001)$.

Next, three scales were formed, corresponding to the factors obtained. To ascertain whether any of the items needed to be reflected, the principal axis of each of the scales were determined. All the reflections made on logical grounds were confirmed. Following this the three scales were subjected to item analysis.

The means and standard deviations of the item statistics in respect of Scale I (Autonomy) are shown in Table 4.

Table 4 shows that the mean of the item means is 5,318 , which is above average, judged on a seven-point scale. The mean of the item-total correlations is 0,486 , which indicates a high internal consistency of the items in the scale. This is supported by the Cronbach alpha reliability coefficient of 0,881 . No items were rejected.

The means and standard deviations of the item statistics in respect of Scale II (External Control) are given in Table 5.

TABLE 3

ROTATED FACTOR MATRIX (DIRECT OBLIMIN)

\begin{tabular}{|c|c|c|c|c|c|c|}
\hline Variables & & K & Factor I & Factor II & Factor III & $\mathbf{h}_{\mathrm{j}}^{2}$ \\
\hline Subtest 5: Items $2,5,22,23,24,25,29,67$ & & 8 & 0,650 & 0,051 & $+0,096$ & 0,476 \\
\hline Subtest 2 : Items $3,30,44,46,70,73^{*}, 74,81,82,83$ & & 10 & 0,632 & $-0,161$ & $+0,140$ & 0,610 \\
\hline Subtest 10: Items $14,15^{*}, 28$ & & 3 & 0,594 & $-0,051$ & $+0,027$ & 0,393 \\
\hline Subtest 8 : Items $1 *, 13,62,66,68$ & & 5 & 0,498 & $-0,213$ & $+0,169$ & 0,491 \\
\hline Subtest 17: Item 64 & & 1 & 0,373 & 0,036 & $-0,034$ & 0,120 \\
\hline Subtest 18: Item 16 & & 1 & 0,181 & 0,016 & $+0,023$ & 0,036 \\
\hline Subtest 4 : Items $4,9,45,47,50,51,57,58,65,80,84$ & & 11 & 0,105 & 0,790 & $-0,022$ & 0,586 \\
\hline Subtest 6 : Items $20,43,52,53,56,88$ & & 6 & $-0,073$ & 0,638 & $-0,025$ & 0,451 \\
\hline Subtest 15: Items 38,39 & & 2 & 0,080 & 0,576 & $-0,016$ & 0,364 \\
\hline Subtest 3: Items $12,34,35,36,41,79$ & & 6 & 0,089 & 0,554 & $-0,011$ & 0,284 \\
\hline Subtest 11: Items $21,71,72$ & & 3 & $-0,321$ & 0,551 & $+0,238$ & 0,452 \\
\hline Subtest 14: Item 77 & & 1 & 0,014 & 0,337 & $-0,068$ & 0,122 \\
\hline Subtest 1: Items $6,7,10,27,32,37,42,48,49,61,63,75,76,78,85,87$ & & 16 & $-0,041$ & $-0,099$ & $+0,895$ & 0,802 \\
\hline Subtest 9: Items $18,19,26,31$ & & 4 & 0,085 & 0,197 & $+0,473$ & 0,268 \\
\hline Subtest 12: Items 55,59 & & 2 & 0,104 & $-0,072$ & $+0,465$ & 0,300 \\
\hline Subtest 13: Items 60,86 & & 2 & $-0,011$ & 0,004 & $+0,394$ & 0,151 \\
\hline Subtest 7: Items $8,33,40,54$ & & 4 & 0,065 & $-0,192$ & $+0,346$ & 0,215 \\
\hline Subtest 19: Item 69 & & 1 & 0,209 & 0,001 & $+0,308$ & 0,205 \\
\hline Subtest $16:$ Items $11^{*}, 17$ & & 2 & 0,159 & $-0,241$ & $+0,264$ & 0,244 \\
\hline Number of items per factor & & 88 & 28 & 29 & 31 & \\
\hline \multicolumn{7}{|l|}{ Note. Factor III has been reflected } \\
\hline \multicolumn{7}{|c|}{ INTERCORRELATIONS OF FACTORS } \\
\hline Variables & Autonomy & \multicolumn{3}{|c|}{ External control } & \multicolumn{2}{|r|}{ Internal control } \\
\hline Factor I & 1,000 & \multicolumn{3}{|c|}{$-0,324$} & \multicolumn{2}{|r|}{$+0,521$} \\
\hline Factor II & $-0,324$ & \multicolumn{3}{|c|}{1,000} & \multicolumn{2}{|r|}{$-0,174$} \\
\hline Factor III & $+0,521$ & \multicolumn{3}{|c|}{$-0,174$} & \multicolumn{2}{|r|}{1,000} \\
\hline
\end{tabular}

Note. Factor III has been reflected

Factor I = Autonomy

Factor II = External control

Factor III = Internal control 
TABLE 4

MEANS AND STANDARD DEVIATIONS OF THE ITEM STATISTICS IN RESPECT OF SCALE I OF THE LCI: AUTONOMY

\begin{tabular}{lcccc}
\hline & $\begin{array}{c}\text { Mean of } \\
\text { items } \\
\overline{\mathrm{X}}_{\mathrm{g}}\end{array}$ & $\begin{array}{c}\text { Standard } \\
\text { deviation of } \\
\text { items }\left(\mathbf{S}_{\mathrm{g}}\right)\end{array}$ & $\begin{array}{c}\text { Item-test } \\
\text { correlations } \\
\left(\mathrm{r}_{\mathrm{gx}}\right)\end{array}$ & $\begin{array}{c}\text { Index of } \\
\text { reliability of } \\
\text { items }\left(\mathbf{r}_{\mathrm{gx}} \mathbf{s}_{\mathrm{g}}\right)\end{array}$ \\
\hline Mean & 5,318 & 1,247 & 0,486 & 0,598 \\
$\mathrm{SD}$ & 0,432 & 0,203 & 0,081 & 0,098 \\
\hline
\end{tabular}

Cronbach alpha $=0,881$

Mean of test $=148,900$

Standard deviation $=16,726$

Number of items $=28$

$\mathrm{N}=3033$

Note. Items 1, 15 and 73 have been reflected

TABLE 5

MEANS AND STANDARD DEVIATIONS OF THE ITEM STATISTICS IN RESPECT OF SCALE II OF THE LCI: EXTERNAL CONTROL

\begin{tabular}{lcccc}
\hline & $\begin{array}{c}\text { Mean of } \\
\text { items } \\
\overline{\mathrm{X}}_{\mathrm{g}}\end{array}$ & $\begin{array}{c}\text { Standard } \\
\text { deviation of } \\
\text { items }\left(\mathbf{S}_{\mathrm{g}}\right)\end{array}$ & $\begin{array}{c}\text { Item-test } \\
\text { correlations } \\
\left(\mathbf{r}_{\mathrm{gx}}\right)\end{array}$ & $\begin{array}{c}\text { Index of } \\
\text { reliability of } \\
\text { items }\left(\mathbf{r}_{\mathrm{gx}} \mathbf{s}_{\mathrm{g}}\right)\end{array}$ \\
\hline Mean & 3,376 & 1,530 & 0,484 & 0,740 \\
$\mathrm{SD}$ & 0,723 & 0,126 & 0,075 & 0,123 \\
\hline
\end{tabular}

Cronbach alpha $=0,881$

Mean of test $=97,912$

Standard deviation $=21,461$

Number of items $=29$

$\mathrm{N}=3033$

Note. No items have been reflected

Table 5 indicates that the mean of the item means is 3,376 , which is below average, judged on a seven-point scale. The mean of the itemtotal correlations is 0,484 , which indicates a high internal consistency of the items in the scale. This is supported by a Cronbach alpha reliability coefficient of 0,881 . No items were rejected.

The means and standard deviations of the item statistics in respect of Scale III (Internal Control) are given in Table 6.

TABLE 6

MEANS AND STANDARD DEVIATIONS OF THE ITEM STATISTICS IN RESPECT OF SCALE III OF THE LCI: INTERNAL CONTROL

\begin{tabular}{lcccc}
\hline & $\begin{array}{c}\text { Mean of } \\
\text { items } \\
\overline{\mathrm{X}}_{\mathrm{g}}\end{array}$ & $\begin{array}{c}\text { Standard } \\
\text { deviation of } \\
\text { items }\left(\mathrm{S}_{\mathrm{g}}\right)\end{array}$ & $\begin{array}{c}\text { Item-test } \\
\text { correlations } \\
\left(\mathbf{r}_{\mathrm{gx}}\right)\end{array}$ & $\begin{array}{c}\text { Index of } \\
\text { reliability of } \\
\text { items }\left(\mathbf{r}_{\mathrm{gx}} \mathbf{s}_{\mathrm{g}}\right)\end{array}$ \\
\hline Mean & 5,939 & 1,101 & 0,428 & 0,465 \\
SD & 0,301 & 0,174 & 0,063 & 0,068 \\
\hline
\end{tabular}

Cronbach alpha $=0,852$

Mean of test $=184,115$

Standard deviation $=14,392$

Number of items $=31$

$\mathrm{N}=3033$

Note. Item 11 has been reflected

From Table 6 it can be seen that the mean of the item means is 5,939 , which is above average judged on a seven-point scale. The mean of the item-total correlations is 0,428 , which indicates a high internal consistency of the items in the scale. This is supported by a Cronbach alpha reliability coefficient of 0,852 . No items were rejected.

By virtue of the positive findings of the analysis, it was decided to prepare a set of norms for the 2003 edition of the LCI.
In the preparation of the norms the same sample as was used in the factor analysis of the LCI, was used. Complete records in respect of 3033 students were available. The standard scores in respect of Autonomy, External Control and Internal Control are given in Tables 7, 8 and 9 respectively.

TABLE 7

TRANSFORMATION OF RAW SCORES TO STANDARD SCORES IN RESPECT OF THE LCI: AUTONOMY

\begin{tabular}{lllc}
\hline Raw score & Stanines & Raw score & Stens \\
\hline 0 to 119 & 1 & 0 to 114 & 1 \\
120 to 127 & 2 & 115 to 123 & 2 \\
128 to 136 & 3 & 124 to 132 & 3 \\
137 to 145 & 4 & 133 to 140 & 4 \\
146 to 153 & 5 & 141 to 149 & 5 \\
154 to 161 & 6 & 150 to 157 & 6 \\
162 to 169 & 7 & 158 to 165 & 7 \\
170 to 177 & 8 & 166 to 173 & 8 \\
178 to 194 & 9 & 174 to 180 & 9 \\
\hline
\end{tabular}

TABLE 8

TrANSFORMATION OF RAW SCORES TO STANDARD SCORES IN RESPECT OF THE LCI: EXTERNAL CONTROI

\begin{tabular}{lllc}
\hline Raw score & Stanines & Raw score & Stens \\
\hline 0 to 61 & 1 & 0 to 56 & 1 \\
62 to 72 & 2 & 57 to 66 & 2 \\
73 to 82 & 6 & 67 to 77 & 3 \\
83 to 94 & 4 & 78 to 88 & 4 \\
95 to 104 & 5 & 89 to 99 & 5 \\
105 to 115 & 6 & 100 to 109 & 6 \\
116 to 125 & 7 & 110 to 120 & 7 \\
126 to 136 & 8 & 121 to 130 & 8 \\
137 to 170 & 9 & 131 to 141 & 9 \\
& & 142 to 170 & 10 \\
\hline
\end{tabular}

TABLE 9

TRANSFORMATION OF RAW SCORES TO STANDARD SCORES IN RESPECT OF THE LCI: INTERNAL CONTROL

\begin{tabular}{lllc}
\hline Raw score & Stanines & Raw score & Stens \\
\hline 0 to 157 & 1 & 0 to 153 & 1 \\
158 to 165 & 2 & 154 to 161 & 2 \\
166 to 173 & 3 & 162 to 169 & 3 \\
174 to 181 & 4 & 170 to 177 & 4 \\
182 to 188 & 5 & 178 to 184 & 5 \\
189 to 195 & 6 & 185 to 192 & 7 \\
196 to 201 & 7 & 193 to 198 & 8 \\
202 to 207 & 8 & 199 to 204 & 9 \\
208 to 217 & 9 & 205 to 209 & 10 \\
\hline
\end{tabular}




\section{THE FACTOR STRUCTURE AND METRICAL PROPERTIES OF THE 16PF (VERSION 5)}

Sample

Essentially the same sample as was used in the analysis of the LCI, was used with the 16PF. Complete records were available in respect of 3089 participants.

\section{Measuring instrument}

The Sixteen Personality Factor Questionnaire (Fifth Edition) was adapted for use in South Africa by the local distributors of the test (Jopie van Rooyen \& Partners SA (Pty) Ltd.) in collaboration with the Institute for Personality and Ability Testing, Champaign, Illinois. Particular attention was paid to language issues, because many American idiomatic expressions are unfamiliar in South Africa.

As the $16 \mathrm{PF}$ is widely used in South Africa and an appropriate administrator's manual is available it will not be described here in detail (Cattell, Cattell \& Cattell, 1993; Russell \& Karol, 1994).
The procedure that was followed in the analysis of the 16PF differs from that used with the LCI in as much as the scoring of the 16 primary factors were taken as given. Only the essential results are given here.

\section{RESULTS (SECTION 1)}

To start off the 16 primary factors were intercorrelated. The matrix of intercorrelations of the factors is given in Table 10.

Next, the eigenvalues of the unreduced intercorrelation matrix were computed. The eigenvalues are given in Table 11 .

From Table 11 it can be seen that six of the eigenvalues are greater than unity suggesting six factors according to Kaiser's criterion (1961). Accordingly six factors were extracted and rotated to simple structure by means of a Direct Oblimin rotation. The rotated factor matrix is given in Table 12 .

Table 12 shows that five of the global factors are reasonably well determined with three or more moderate to high loadings. Factor 5 has only two moderate loadings.

TABLE 10

MATRIX OF INTERCORRELATIONS OF THE PRIMARY FACTORS OF THE 16PF

\begin{tabular}{|c|c|c|c|c|c|c|c|c|c|}
\hline Correlation & $\begin{array}{c}\text { Warmth } \\
\text { (A) }\end{array}$ & $\begin{array}{l}\text { Reasoning } \\
\text { (B) }\end{array}$ & $\begin{array}{l}\text { Emotional } \\
\text { Stability } \\
\text { (C) }\end{array}$ & $\begin{array}{c}\text { Dominance } \\
\text { (E) }\end{array}$ & $\begin{array}{l}\text { Liveliness } \\
\text { (F) }\end{array}$ & $\begin{array}{c}\text { Rule- } \\
\text { consciousness } \\
\text { (G) }\end{array}$ & $\begin{array}{c}\text { Social } \\
\text { Boldness } \\
\text { (H) }\end{array}$ & $\begin{array}{c}\text { Sensitivity } \\
\text { (I) }\end{array}$ & $\begin{array}{c}\text { Vigilance } \\
\text { (L) }\end{array}$ \\
\hline Warmth (A) & 1,000 & $-0,116$ & 0,089 & 0,094 & 0,314 & 0,096 & 0,319 & 0,448 & $-0,028$ \\
\hline Reasoning (B) & $-0,116$ & 1,000 & 0,074 & 0,021 & 0,113 & $-0,011$ & $-0,004$ & $-0,047$ & $-0,056$ \\
\hline Emotional Stability (C) & 0,089 & 0,074 & 1,000 & 0,236 & 0,206 & 0,140 & 0,393 & $-0,113$ & $-0,227$ \\
\hline Dominance (E) & 0,094 & 0,021 & 0,236 & 1,000 & 0,197 & 0,033 & 0,413 & $-0,054$ & 0,084 \\
\hline Liveliness (F) & 0,314 & 0,113 & 0,206 & 0,197 & 1,000 & $-0,202$ & 0,446 & 0,062 & $-0,050$ \\
\hline Rule-consciousness (G) & 0,096 & $-0,011$ & 0,140 & 0,033 & $-0,202$ & 1,000 & $-0,021$ & 0,044 & $-0,064$ \\
\hline Social Boldness $(\mathrm{H})$ & 0,319 & $-0,004$ & 0,393 & 0,413 & 0,446 & $-0,021$ & 1,000 & 0,038 & $-0,102$ \\
\hline Sensitivity (I) & 0,448 & $-0,047$ & $-0,113$ & $-0,054$ & 0,062 & 0,044 & 0,038 & 1,000 & 0,017 \\
\hline Vigilance (L) & $-0,028$ & $-0,056$ & $-0,227$ & 0,084 & $-0,050$ & $-0,064$ & $-0,102$ & 0,017 & 1,000 \\
\hline Abstractedness (M) & $-0,023$ & 0,034 & $-0,325$ & $-0,071$ & 0,073 & $-0,291$ & $-0,104$ & 0,162 & 0,173 \\
\hline Privateness $(\mathrm{N})$ & $-0,342$ & 0,041 & $-0,195$ & $-0,134$ & $-0,243$ & 0,004 & $-0,419$ & $-0,082$ & 0,253 \\
\hline Apprehension $(\mathrm{O})$ & 0,123 & $-0,037$ & $-0,523$ & $-0,218$ & $-0,091$ & 0,072 & $-0,308$ & 0,233 & 0,195 \\
\hline Openness to Change (Q1) & 0,143 & 0,017 & 0,129 & 0,218 & 0,154 & $-0,074$ & 0,243 & 0,118 & 0,000 \\
\hline Self-reliance (Q2) & $-0,388$ & 0,038 & $-0,264$ & $-0,115$ & $-0,472$ & 0,036 & $-0,379$ & $-0,019$ & 0,160 \\
\hline Perfectionism (Q3) & $-0,022$ & $-0,105$ & 0,056 & 0,116 & $-0,228$ & 0,414 & $-0,038$ & $-0,003$ & 0,067 \\
\hline Tension (Q4) & $-0,132$ & 0,073 & $-0,310$ & 0,152 & 0,032 & $-0,184$ & $-0,087$ & 0,019 & 0,236 \\
\hline \multicolumn{10}{|l|}{ Note. $\mathrm{N}=3089$} \\
\hline & $\begin{array}{c}\text { Abstractedness } \\
\text { (M) }\end{array}$ & $\begin{array}{c}\text { Privateness } \\
\text { (N) }\end{array}$ & \multicolumn{2}{|c|}{$\begin{array}{c}\text { Apprehension } \\
\text { (O) }\end{array}$} & $\begin{array}{c}\text { Openness } \\
\text { to Change } \\
\text { (Q1 }\end{array}$ & \multicolumn{2}{|c|}{$\begin{array}{c}\text { Self-reliance } \\
\text { (Q2) }\end{array}$} & $\begin{array}{l}\text { Perfectionism } \\
\text { (Q3) }\end{array}$ & $\begin{array}{c}\text { Tension } \\
\text { (Q4) }\end{array}$ \\
\hline & $-0,023$ & $-0,342$ & \multicolumn{2}{|c|}{0,123} & 0,143 & \multicolumn{2}{|l|}{$-0,388$} & $-0,022$ & $-0,132$ \\
\hline & 0,034 & 0,041 & \multicolumn{2}{|c|}{$-0,037$} & 0,017 & \multicolumn{2}{|l|}{0,038} & $-0,105$ & 0,073 \\
\hline & $-0,325$ & $-0,195$ & \multicolumn{2}{|c|}{$-0,523$} & 0,129 & \multicolumn{2}{|l|}{$-0,264$} & 0,056 & $-0,310$ \\
\hline & $-0,071$ & $-0,134$ & \multicolumn{2}{|c|}{$-0,218$} & 0,218 & \multicolumn{2}{|l|}{$-0,115$} & 0,116 & 0,152 \\
\hline & 0,073 & $-0,243$ & \multicolumn{2}{|c|}{$-0,091$} & 0,154 & \multicolumn{2}{|l|}{$-0,472$} & $-0,228$ & 0,032 \\
\hline & $-0,291$ & 0,004 & \multicolumn{2}{|c|}{0,072} & $-0,074$ & \multicolumn{2}{|l|}{0,036} & 0,414 & $-0,184$ \\
\hline & $-0,104$ & $-0,419$ & \multicolumn{2}{|c|}{$-0,308$} & 0,243 & \multicolumn{2}{|l|}{$-0,379$} & $-0,038$ & $-0,087$ \\
\hline & 0,162 & $-0,082$ & \multicolumn{2}{|c|}{0,233} & 0,118 & \multicolumn{2}{|l|}{$-0,019$} & $-0,003$ & 0,019 \\
\hline & 0,173 & 0,253 & \multicolumn{2}{|c|}{0,195} & 0,000 & \multicolumn{2}{|l|}{0,160} & 0,067 & 0,236 \\
\hline & 1,000 & 0,061 & \multicolumn{2}{|c|}{0,224} & 0,271 & \multicolumn{2}{|l|}{0,165} & $-0,306$ & 0,109 \\
\hline & 0,061 & 1,000 & \multicolumn{2}{|c|}{0,108} & $-0,141$ & \multicolumn{2}{|l|}{0,349} & 0,098 & 0,160 \\
\hline & 0,224 & 0,108 & \multicolumn{2}{|c|}{1,000} & $-0,075$ & \multicolumn{2}{|l|}{0,100} & 0,111 & 0,209 \\
\hline & 0,271 & $-0,141$ & & 075 & 1,000 & $-0,092$ & & $-0,084$ & $-0,184$ \\
\hline & 0,165 & 0,349 & & 100 & $-0,092$ & 1,000 & & 0,139 & 0,148 \\
\hline & $-0,306$ & 0,098 & & 111 & $-0,084$ & 0,139 & & 1,000 & $-0,009$ \\
\hline & 0,109 & 0,160 & & 209 & $-0,184$ & 0,148 & & 0,009 & 1,000 \\
\hline
\end{tabular}


TABLE 11

EIGENVALUES OF UNREDUCED INTERCORRELATION MATRIX OF 16PF

\begin{tabular}{lccc}
\hline Root & Eigenvalue & \% of variance & Cumulative \% \\
\hline 1 & 3,159 & 19,743 & 19,743 \\
2 & 2,104 & 13,148 & 32,891 \\
3 & $\mathbf{1 , 7 1 8}$ & 10,740 & 43,631 \\
4 & $\mathbf{1 , 4 1 5}$ & $\mathbf{8 , 8 4 4}$ & $\mathbf{5 2 , 4 7 5}$ \\
5 & $\mathbf{1 , 2 0 3}$ & $\mathbf{7 , 5 2 0}$ & $\mathbf{5 9 , 9 9 5}$ \\
6 & $\mathbf{1 , 0 2 0}$ & $\mathbf{6 , 3 7 5}$ & $\mathbf{6 6 , 3 7 0}$ \\
7 & 0,836 & 5,226 & 71,596 \\
8 & 0,787 & 4,918 & 76,514 \\
9 & 0,640 & 4,000 & 80,513 \\
10 & 0,549 & 3,434 & 83,947 \\
11 & 0,532 & 3,327 & 87,274 \\
12 & 0,463 & 2,897 & 90,171 \\
13 & 0,426 & 2,665 & 92,836 \\
14 & 0,394 & 2,460 & 95,296 \\
15 & 0,379 & 2,369 & 97,665 \\
16 & 0,374 & 2,335 & 100,000 \\
\hline Trace & 16,000 & & \\
\hline
\end{tabular}

Factor 1 has high loadings on Liveliness $(0,901)$ and Grouporientation $(0,492)$, and a low loading on Warmth $(0,344)$. It thus relates to enthusiasm, spontaneity and attention seeking, particularly in social situations.

Factor 2 has substantial loadings on Perfectionism $(0,671)$, Ruleconsciousness $(0,600)$ and Groundedness $(0,349)$. Persons scoring high on Factor 2 are thus perfectionistic in whatever they do, they strictly observe cultural standards of right and wrong and are practically minded in what they do.

Factor 3 has high to moderate loadings on Dominance $(0,709)$, Social Boldness $(0,570)$, Self-assuredness $(0,490)$ and Reactivity $(-0,402)$. Persons scoring high on Factor 3 tend to exert their will over others, they are forceful and tend to initiate social contacts. They are not shy in the face of new social settings, are selfassured and react to life experiences.

Factor 4 has high to moderate loadings on Tension $(0,731)$, Emotional Stability $(0,453)$, Vigilance $(0,396)$ and Selfassuredness $(0,371)$. Persons scoring high on Factor 4 are characterised by high nervous tension, they take life in their stride and manage events in a balanced, adaptive way, they are vigilant about others' motives, and are not troubled about their sense of adequacy.

Factor 5 has moderate loadings on Abstractedness $(0,580)$ and Openness to Change $(0,571)$. Persons scoring high on this factor are more orientated to internal mental processes and ideas than to practicalities. They are constantly looking for ways to improve things and enjoy experimenting.

Factor 6 has high to moderate loadings on Warmth $(0,684)$, Sensitivity $(0,443)$ and Forthrightness $(0,350)$. Persons scoring high on this factor are warmly involved with people, and they rely on empathy and sensitivity in their dealing with others. They readily talk to others about themselves.

The communalities of Factor B (Reasoning) and Factor L (Vigilance) are very low, indicating that these two factors have little in common with the other primary factors.

TABLE 12

ROTATED FACTOR MATRIX OF SIXTEEN PERSONALITY FACTOR QUESIONNAIRE (DIRECT OBLIMIN ROATAION)

\begin{tabular}{|c|c|c|c|c|c|c|c|}
\hline Variables & Factor 1 & Factor $2^{*}$ & Factor $3 *$ & Factor 4 & Factor 5 & Factor $6^{*}$ & $\mathbf{h}_{\mathrm{j}}^{2}$ \\
\hline Factor A: Warmth & 0,344 & 0,066 & 0,016 & $-0,032$ & 0,057 & 0,684 & 0,700 \\
\hline Factor B: Reasoning & 0,110 & 0,027 & $-0,013$ & 0,004 & 0,028 & $-0,208$ & 0,050 ** \\
\hline Factor $C^{*}$ : Emotional Stability & 0,148 & 0,154 & 0,402 & $-0,453$ & $-0,038$ & $-0,155$ & 0,559 \\
\hline Factor E : Dominance & 0,048 & 0,125 & 0,709 & 0,289 & 0,125 & 0,003 & 0,544 \\
\hline Factor F : Liveliness & 0,901 & $-0,070$ & 0,024 & 0,087 & 0,054 & $-0,137$ & 0,830 \\
\hline Factor G : Rule-consciousness & $-0,010$ & 0,600 & $-0,039$ & $-0,159$ & $-0,039$ & 0,064 & 0,409 \\
\hline Factor H : Social Boldness & 0,290 & $-0,043$ & 0,570 & $-0,055$ & 0,050 & 0,180 & 0,585 \\
\hline Factor I : Sensitivity & 0,080 & 0,037 & $-0,131$ & 0,069 & 0,190 & 0,443 & $0,294^{*}$ \\
\hline Factor L : Vigilance & $-0,034$ & 0,074 & 0,008 & 0,396 & 0,137 & $-0,044$ & $0,202 * *$ \\
\hline Factor M : Abstractedness & $-0,065$ & $-0,349$ & $-0,168$ & 0,155 & 0,580 & 0,008 & 0,604 \\
\hline Factor N : Privateness & $-0,163$ & 0,147 & $-0,221$ & 0,198 & 0,044 & $-0,350$ & $0,333^{*}$ \\
\hline Factor $\mathrm{O}^{*}$ : Apprehension & 0,112 & 0,164 & $-0,490$ & 0,371 & 0,085 & 0,240 & 0,537 \\
\hline Factor Q1: Openness to Change & 0,016 & $-0,028$ & 0,224 & $-0,168$ & 0,571 & 0,044 & 0,400 \\
\hline Factor Q2*: Self-reliance & $-0,492$ & 0,069 & $-0,088$ & 0,158 & 0,152 & $-0,195$ & 0,435 \\
\hline Factor Q3: Perfectionism & $-0,062$ & 0,671 & 0,082 & 0,096 & $-0,058$ & $-0,006$ & 0,498 \\
\hline Factor Q4: Tension & 0,017 & $-0,139$ & 0,129 & 0,731 & $-0,198$ & $-0,020$ & 0,518 \\
\hline
\end{tabular}

FACTOR CORRELATION MATRIX (16PF)

\begin{tabular}{lcccccc}
\hline Variables & Factor 1 & Factor 2 & Factor 3 & Factor 4 & Factor 5 \\
\hline Factor 1 & 1,000 & $-0,220$ & 0,296 & $-0,156$ & 0,075 \\
Factor 2* & $-0,220$ & 1,000 & 0,025 & 0,003 & $-0,115$ \\
Factor 3* & 0,296 & 0,025 & 1,000 & $-0,233$ & $-0,034$ & 0,179 \\
Factpr 4 & $-0,156$ & 0,003 & $-0,233$ & $-0,028$ & $-1,000$ & 0,151 \\
Factor 5 & 0,075 & $-0,115$ & $-0,034$ & 0,151 & 0,072 \\
Factor 6* & 0,179 & 0,127 & $-0,028$ & $-0,072$ & 0,094 \\
\hline
\end{tabular}

Note. Kaiser-Meyer-Olkin Measure of Sampling Adequacy $=0,704$

*Factors 2, 3 and 6 have been reflected

*Factors C, O and Q2 have been reflected 
The intercorrelations between the global factors are also given in Table 12. From this matrix it is clear that the mutual intercorrelations between the factors are very low. The global factors are therefore essentially independent of one another.

To determine the metrical properties of the $16 \mathrm{PF}$ the reliabilities of the 16 primary factors were determined with the aid of Cronbach alpha. The obtained alpha coefficients are given in Table 13.

\section{TABLE 13}

Reliabilities of THE PRIMARY FACtoRs OF THE 16PF (Version 5)

\begin{tabular}{lc}
\hline Primary factors & Cronbach Alpha \\
\hline FACTOR A: WARMTH & 0,686 \\
FACTOR B: REASONING & 0,559 \\
FACTOR C: EMOTIONAL STABILITY & 0,701 \\
FACTOR E: DOMINANCE & 0,616 \\
FACTOR F: LIVELINESS & 0,705 \\
FACTOR G: RULE-CONSCIOUSNESS & 0,651 \\
FACTOR H: SOCIAL BOLDNESS & 0,858 \\
FACTOR I: SENSITIVITY & 0,758 \\
FACTOR L: VIGILANCE & 0,466 \\
FACTOR M: ABSTRACTEDNESS & 0,697 \\
FACTOR N: PRIVATENESS & 0,724 \\
FACTOR O: APPREHENSION & 0,687 \\
FACTOR Q1: OPENNESS TO CHANGE & 0,593 \\
FACTOR Q2: SELF-RELIANCE & 0,707 \\
FACTOR Q3: PERFECTIONISM & 0,693 \\
FACTOR Q4: TENSION & 0,714 \\
\hline
\end{tabular}

From Table 13 it can be seen that the alpha coefficients range from 0,466 to 0,858 . The reliabilities in respect of Vigilance, Reasoning and Openness to Change are less than 0,600.

To estimate the reliabilities of the global factors, composites were formed by combining all the primary factors with substantial loadings on a particular factor. The average reliability of the components and the average intercorrelation of the components are given in Table 14.

TABLE 14

RELIABILITY OF THE VARIOUS COMPOSITE SCORES OF THE 16PF

\begin{tabular}{lcccc}
\hline Composite & $\begin{array}{c}\text { Average } \\
\text { reliability of } \\
\text { components }\end{array}$ & $\begin{array}{c}\text { Average inter- } \\
\text { correlation } \\
\text { of the } \\
\text { components }\end{array}$ & $\begin{array}{c}\text { Reliability of } \\
\text { the components }\end{array}$ & K \\
\hline 1 Liveliness & 0,6993 & 0,3913 & 0,831 & 3 \\
2 Perfectionism & 0,6803 & 0,3370 & 0,809 & 3 \\
3 Dominance & 0,7155 & 0,3485 & 0,861 & 4 \\
4 Tension & 0,6420 & 0,2833 & 0,807 & 4 \\
5 Abstractedness & 0,6450 & 0,2710 & 0,721 & 2 \\
6 Warmth & 0,7227 & 0,2907 & 0,825 & 3 \\
\hline
\end{tabular}

The following formula developed by Schepers (1992, p.63) was used to estimate the reliabilities of the global factors:

$$
\begin{aligned}
\rho_{x x^{\prime}} & =\frac{\bar{\rho}_{g g^{\prime}}+(K-1) \bar{\rho}_{g h}}{1+(K-1) \bar{\rho}_{g h}}, \text { where } \\
\rho_{x x} & =\text { reliability of composite } \\
\bar{\rho}_{g g^{\prime}} & =\text { average reliability of components } \\
\bar{\rho}_{g h} & =\text { average intercorrelation of components } \\
K & =\text { number of components }
\end{aligned}
$$

Table 14 shows that the reliabilities of the global factors (composites) vary from 0,721 to 0,861 . All the reliabilities except that of Abstractedness are greater than 0,800.

Next, the relationship between the LCI and 16PF was determined.

\section{METHOD (SECTION 2)}

\section{THE RELATIONSHIP BETWEEN THE LCI AND THE 16PF}

\section{Sample}

As was mentioned earlier the LCI and 16PF were applied to a sample of 3089 first-year university students. Complete records in respect of both instruments were obtained for 2798 participants.

\section{Statistical analysis}

To determine the relationship between the LCI and the 16PF a canonical correlation analysis was done (Cliff, 1987, p.442; Tabachnick \& Fidell, 1983). The obtained canonical variates were rotated to simple structure by means of a target rotation (Browne, 1972a, 1972b, 1993).

\section{RESULTS (SECTION 2)}

As a first step in the analysis, the canonical correlations of the primary factors of the 16PF (IV's) with the three scales of the LCI (DV's) were computed. For the sake of completeness all the primary factors of the 16PF (Version 5) were included, knowing that the loadings in respect of Reasoning, Vigilance and Openness to Change would be depressed. Bartlett's $(1950,1951)$ test of significance was used to determine the number of significant canonical correlations, and is given in Table 15 .

TABLE 15

STATISTICAL SIGNIFICANCE OF CANONICAL CORRELATIONS: BARTLETT'S TEST IN RESPECT OF LCI AND 16PF

\begin{tabular}{lccccccc}
\hline Eigenvalues & $\begin{array}{c}\text { Canonical } \\
\text { corre- } \\
\text { lations }\end{array}$ & $\begin{array}{c}\text { Eigenvalue } \\
\text { removed }\end{array}$ & \multicolumn{4}{c}{$\begin{array}{c}\text { Significance of } \\
\text { remaining eigenvalues }\end{array}$} \\
\hline & & & $\chi^{2}$ & df & p & $\begin{array}{c}\text { Lambda } \\
\text { prime }\end{array}$ \\
\hline 0,434523 & 0,659184 & 0 & 2541,687 & 48 & 0,000001 & 0,401728 \\
0,207303 & 0,455305 & 1 & 952,856 & 30 & 0,000001 & 0,710424 \\
0,103789 & 0,322163 & 2 & 305,398 & 14 & $<0,000001$ & 0,896211 \\
\hline
\end{tabular}

Note. $\mathrm{N}=2798$

From Table 15 it is clear that there are three significant canonical correlations. Accordingly three canonical variates together with their associated canonical correlations, were computed. The complete analysis is given in Table 16. 
TABLE 16

CANONICAL CORRelations OF 16PF (IV's) WITH THE RESPECTIVE MEASURES OF LCI (DV'S)

Correlations of original measures with canonical variates

Variate 1 Variate 2 Variate 3

\begin{tabular}{|c|c|c|c|c|}
\hline \multicolumn{5}{|l|}{ Independent variables } \\
\hline PF 1: Warmth (A) & 0,001 & $-0,096$ & 0,367 & \\
\hline PF 2: Reasoning (B) & 0,097 & $-0,169$ & $-0,318$ & \\
\hline PF 3: Emotional Stability (C) & 0,656 & $-0,337$ & $-0,168$ & \\
\hline PF 4: Dominance (E) & 0,677 & 0,386 & 0,157 & \\
\hline PF 5: Liveliness (F) & 0,108 & 0,399 & 0,023 & \\
\hline PF 6: Rule-consciousness (G) & 0,154 & $-0,544$ & 0,503 & \\
\hline PF 7: Social Boldness (H) & 0,611 & 0,226 & 0,081 & \\
\hline PF 8: Sensitivity (I) & $-0,116$ & $-0,334$ & 0,319 & \\
\hline PF 9: Vigilance (L) & $-0,161$ & 0,386 & 0,355 & \\
\hline PF 10: Abstractedness (M) & $-0,124$ & 0,410 & $-0,114$ & \\
\hline PF 11: Privateness (N) & $-0,248$ & 0,003 & $-0,018$ & \\
\hline PF 12: Apprehension $(\mathrm{O})$ & $-0,545$ & 0,155 & 0,524 & \\
\hline $\begin{array}{l}\text { PF 13: Openness to } \\
\text { Change (Q1) }\end{array}$ & 0,538 & 0,134 & 0,003 & \\
\hline PF 14: Self-reliance Q2) & $-0,053$ & $-0,009$ & 0,046 & \\
\hline PF 15: Perfectionism (Q3) & 0,179 & $-0,266$ & 0,654 & \\
\hline PF 16 : Tension (Q4) & $-0,218$ & 0,304 & 0,034 & \\
\hline $\begin{array}{l}\text { Average } \% \text { variance } \\
\text { accounted for }\end{array}$ & $13,073 \%$ & $9,009 \%$ & $9,348 \%$ & Total: $31,430 \%$ \\
\hline Average $\%$ redundancy & $5,681 \%$ & $1,868 \%$ & $0,970 \%$ & Total: $8,518 \%$ \\
\hline \multicolumn{5}{|l|}{ Dependent variables } \\
\hline LCI 1 : Autonomy & 0,933 & 0,162 & 0,320 & \\
\hline LCI 2 : External Control & $-0,569$ & 0,790 & 0,229 & \\
\hline LCI 3 : Internal Control & 0,357 & $-0,299$ & 0,885 & \\
\hline $\begin{array}{l}\text { Average } \% \text { variance } \\
\text { accounted for }\end{array}$ & $44,077 \%$ & $24,664 \%$ & $31,259 \%$ & Total: $100,00 \%$ \\
\hline Average $\%$ redundancy & $19,153 \%$ & $5,113 \%$ & $3,244 \%$ & Total: $27,510 \%$ \\
\hline Canonical Correlations & 0,659 & 0,455 & 0,322 & \\
\hline
\end{tabular}

Note. $\mathrm{N}=2798$

Variates 1,2 and 3 have been reflected

Table 16 shows that the first canonical variate yielded a canonical correlation of $0,659(p<0,000001)$, the second a canonical correlation of $0,455(\mathrm{p}<0,000001)$ and the third a canonical correlation of $0,322(p<0,000001)$.

From an interpretive point of view it is normally very difficult to identify the components underlying the canonical structure matrix as it resembles an unrotated factor matrix. Rotation to simple structure is therefore necessary. In this regard Cliff $(1987$, p. 456) states that the structure correlations between the observed variables and the canonical variates "can be transformed by the rotational methods of factor analysis, although the same transformation must be applied to the structure correlations of both batteries". Target rotation would seem to be ideal for this purpose (Browne, 1972a, 1972b).

From a theory testing point of view target rotation is more appropriate than the usual rotations to simple structure such as Varimax, Promax, Direct Oblimin, Quartimax, Quartimin, and other procedures. With target rotation the common factor structure of two batteries of tests can be specified on theoretical grounds.

It was therefore decided to rotate the canonical structure correlations to simple structure by means of a Tarrot rotation (Browne, 1993). A target matrix was specified for this purpose. It is based on attribution theory and social learning theory (Heider,
1958; Rotter, 1966) as well as on recent empirical studies of the $16 \mathrm{PF}$ (Hofer \& Eber, 2002, pp. 397-404). The target matrix is given in Table 17, and the rotated matrix in Table 18.

TABLE 17

TARGET MATRIX FOR TARROT ROTATION

\begin{tabular}{lccc}
\hline & Factor 1 & Factor 2 & Factor 3 \\
\hline A & 0,000 & 0,000 & 0,000 \\
B & 0,000 & 9,000 & 0,000 \\
C & 9,000 & 9,000 & 0,000 \\
E & 9,000 & 0,000 & 0,000 \\
F & 0,000 & 0,000 & 0,000 \\
G & 0,000 & 0,000 & 9,000 \\
H & 9,000 & 0,000 & 0,000 \\
I & 0,000 & 0,000 & 0,000 \\
L & 0,000 & 9,000 & 0,000 \\
M & 0,000 & 0,000 & 9,000 \\
N & 0,000 & 0,000 & 0,000 \\
O & 9,000 & 9,000 & 0,000 \\
Q1 & 9,000 & 0,000 & 0,000 \\
Q2 & 0,000 & 0,000 & 0,000 \\
Q3 & 0,000 & 0,000 & 9,000 \\
Q4 & 0,000 & 9,000 & 0,000 \\
LOC1 & 9,000 & 0,000 & 0,000 \\
LOC2 & 0,000 & 9,000 & 0,000 \\
LOC3 & 9,000 & 0,000 & 9,000 \\
\hline
\end{tabular}

Oblique rotation to a partially specified target

TABLE 18

TARROT ROTATION OF CANONICAL CORRELATION FACTOR LOADINGS (16PF \& LCI)

\begin{tabular}{lccc}
\hline Variables & Factor 1 & Factor 2* & Factor 3 \\
\hline Independent variables & & & \\
Factor A : Warmth & 0,022 & $-0,119$ & $\mathbf{0 , 3 6 1}$ \\
Factor B : Reasoning & $-0,042$ & $+0,332$ & $-0,181$ \\
Factor C : Emotional Stability & 0,406 & $+0,630$ & 0,056 \\
Factor E : Dominance & $\mathbf{0 , 7 9 5}$ & $-0,055$ & $-0,029$ \\
Factor F : Liveliness & 0,272 & $-0,256$ & $-0,181$ \\
Factor G : Rule-consciousness & $-0,012$ & $+0,215$ & $\mathbf{0 , 7 1 8}$ \\
Factor H : Social Boldness & $\mathbf{0 , 6 5 1}$ & $+0,070$ & $-0,020$ \\
Factor I : Sensitivity & $-0,193$ & $+0,029$ & $\mathbf{0 , 4 3 6}$ \\
Factor L : Vigilance & 0,085 & $-0,538$ & 0,101 \\
Factor M : Abstractedness & 0,045 & $-0,296$ & $-0,307$ \\
Factor N : Privateness & $-0,223$ & $-0,107$ & $-0,032$ \\
Factor O : Apprehension & $\mathbf{0 , 3 2 9}$ & $-0,627$ & $\mathbf{0 , 3 4 6}$ \\
Factor Q1 : Openness to Change & $-\mathbf{0 , 5 3 5}$ & $+0,142$ & $-0,043$ \\
Factor Q2 : Self-reliance & $-0,042$ & $-0,041$ & 0,044 \\
Factor Q3 : Perfectionism & 0,153 & $-0,054$ & $\mathbf{0 , 7 1 2}$ \\
Factor Q4 : Tension & $-0,055$ & $-0,338$ & $-0,140$ \\
Dependent variables & & & \\
LCI 1: Autonomy & $\mathbf{0 , 9 5 2}$ & $+0,142$ & 0,236 \\
LCI 2: External Control & $-0,125$ & $-0,954$ & $-0,230$ \\
LCI 3: Internal Control & $\mathbf{0 , 4 7 0}$ & $-0,288$ & $\mathbf{0 , 7 7 8}$ \\
\hline
\end{tabular}

Note. Square root of average squared deviation $=0,175438$ *Factor 2 has been reflected

\section{FACTOR CORRELATION MATRIX}

\begin{tabular}{lccc}
\hline & Factor 1 & Factor 2* & Factor 3 \\
\hline Factor 1 & 1,000 & $-0,004$ & 0,030 \\
Factor 2 & $-0,004$ & 1,000 & $-0,043$ \\
Factor 3 & 0,030 & $-0,043$ & 1,000 \\
\hline
\end{tabular}


On theoretical grounds it was expected that persons who are high on Autonomy would be forceful, assertive, socially bold, open to change, emotionally stable and self-assured. Factor 1 of the target matrix was accordingly specified to have loadings on the above-mentioned attributes. Internal Control was included because it is well known that Autonomy and Internal Control are positively correlated.

On theoretical grounds it was expected that persons who are high on External Control would be emotionally unstable, apprehensive, suspicious, tense and concrete in their thinking (Schepers \& Gropp, 2005). Factor 2 of the target matrix was accordingly specified to have high loadings on these variables.

On theoretical grounds it was expected that persons who are high on Internal Control would be rule-conscious, dutiful, perfectionistic, well organised and practical. Factor 3 of the target matrix was therefore specified to have high loadings on these variables.

Table 18 shows that Factors 1 and 2 fit the target matrix very well. Factor 3 has three additional loadings, viz. in respect of Sensitivity, Warmth and Apprehension. The loading on Apprehension $(0,346)$ is low and does not fit in with the rest of the picture.

Furthermore, from Table 18 it can be seen that the three factors are virtually uncorrelated with one another.

Overall, the rotated canonical variate matrix gave a very good fit with the specified target matrix. The square root of the average squared deviation was 0,175 . The obtained factors can therefore be interpreted with confidence.

Factor 1 can be interpreted as Ascendancy coupled with social boldness and autonomy: Persons who are high on this factor are well balanced individuals, they tend to be forceful, socially bold, open to change, and confident that they can overcome problems on their own.Factor 2 can be interpreted as Emotional Stability. Persons who are high on this factor are emotionally stable, selfassured, trusting and relaxed. They normally have low scores on External Control.

Factor 3 can be interpreted as Rule-consciousness: Persons who are high on this factor are rule-conscious, dutiful, perfectionistic, well organised and practical. They normally have quite high scores on Internal Control.

\section{DISCUSSION}

\section{THE FACTOR STRUCTURE AND METRICAL PROPERTIES OF THE LCI AND 16PF}

The factor analysis of the LCI substantiated the three-factorstructure previously found by de Bruin (2004), Schepers (2004), and Schepers and Gropp (2005). The obtained factors were interpreted as Autonomy, External Control and Internal Control.

Cronbach alpha coefficients of 0,$881 ; 0,881$ and 0,852 were obtained for Autonomy, External Control and Internal Control respectively. No items were rejected.

Conversion tables for transforming the raw scores of the three scales to standard scores were prepared in respect of a sample of 3033 participants.

The factor analysis of the 16PF produced six global factors. Five of the six factors were well determined and one was a doublet. The reliabilities of the primary factors ranged from 0,466 to 0,858 . Three of the primary factors had reliabilities less than 0,600 . It is therefore clear that a number of items of Factors B, L and Q1 of the 16PF will have to be revised or replaced with better ones.
The reliabilities of the global factors are more promising. The reliabilities of the composites range from 0,721 to 0,861 . Only one of the coefficients is less than 0,800 . It is therefore clear that more weight should be attached to the global factors than to the primary factors.

The obtained global factors were identified as follows:

Factor 1: Liveliness

Factor 2: Perfectionism

Factor 3: Dominance

Factor 4: Tension

Factor 5: Abstractedness

Factor 6: Warmth

\section{THE RELATIONSHIP BETWEEN THE LCI AND THE 16PF}

From the canonical correlation analysis three significant canonical correlations were obtained. To interpret the loadings of the canonical variates a target rotation was done.

The first factor had high loadings on Autonomy, Dominance, Social Boldness, Openness to Change, Emotional Stability, and Internal Control. It was therefore interpreted as Ascendancy coupled with Social Boldness and Autonomy.

The second factor had high loadings on External Control (negative), Emotional Stability, Self-assurance, Trust, and Relaxedness. It was therefore interpreted as Emotional stability. It needs to be stressed that this factor is associated with low scores on External Control.

The third factor had high loadings on Rule-consciousness, Internal Control, Perfectionism and Sensitivity. It was therefore interpreted as Rule-consciousness.

From the foregoing it is clear that the LCI (2003) is now ready for use on a large scale. Additional norms should be prepared for a variety of groups. The 16PF (Version 5) needs to be revised thoroughly.

\section{ACKNOWLEDGEMENTS}

I hereby wish to thank Riëtte Eiselen and Wilhelm Koster of the Statistical Consultation Service of the University of Johannesburg for all the hours of computational work done for me. I value it very highly.

A special word of thanks to Annetjie Boshoff and her assistant Afton Walters for typing the manuscript at short notice.

\section{REFERENCES}

Antonovsky, A. (1993). The structure and properties of the Sense of Coherence Scale. Social Science and Medicine, 36 (6), 725-733.

Bar-On, R. (1997). BarOn Emotional Quotient Inventory Technical manual. Toronto: Multi-Health System, Inc.

Bartlett, M.S. (1950). Tests of significance in factor analysis. British Journal of Psychology, 3, 77-85.

Bartlett, M.S. (1951). A further note on tests of significance in factor analysis. British Journal of Psychology, Statistical Section, 4, 1-2.

Bloxom, B. (1972). The Personal Orientation Inventory. In O.K. Buros (Ed.), The Seventh Mental Measurements Yearbook (pp.290-292). New Jersey: Gryphon Press.

Browne, M.W. (1972a). Oblique rotation to a partially specified target. British Journal of Mathematical and Statistical Psychology, 25, 207-212.

Browne, M.W. (1972b). Orthogonal rotation to a partially specified target. British Journal of Mathematical and Statistical Psychology, 25, 115-120. 
Browne, M.W. (1993). Rotation to a partially specified target. Tarrot version 2, Department of Psychology, University of Illinois, Columbus.

Cattell, R.B., Cattell, A.K., \& Cattell, H.E. (1993). The Sixteen Personality Factor Questionnaire, Fifth Edition. Champaign, IL: Institute for Personality and Ability Testing, Inc.

Cliff, N. (1987). Analyzing multivariate data. New York: Harcourt Brace Jovanovich, Publishers.

De Bruin, G.P. (2004). Problems with the factor analysis of items: Solutions based on item response theory and item parcelling. SA Journal of Industrial Psychology, 30 (4), 16-26.

Heider, F. (1958). Psychology of interpersonal relations. New York: Wiley.

Hofer, S.M. \& Eber, H.W. (2002). Second-order factor structure of the Cattell sixteen personality factor questionnaire. In B. de Raad \& M. Perugini (Eds.). Big five assessment. Ashland: Hogrefe \& Huber Publishers.

Kaiser, H.F. (1961). A note on Guttman's lower bound for the number of common factors. British Journal of Statistical Psychology, 14 (1), 1.
Knapp, R. (1976). Handbook for the Personal Orientation Inventory. San Diego, Calif: Edits.

Rotter, J.B. (1966). Generalized expectancies for internal versus external control of reinforcement. Psychological Monographs, 80, 1-28.

Russell, M.T. \& Karol, D.L. (1994). The 16PF fifth edition administrator's manual. Champaign, IL: Institute for Personality and Ability Testing, Inc.

Schepers, J.M. (1992). Toetskonstruksie: Teorie en praktyk. Johannesburg: RAU-Drukpers.

Schepers, J.M. (2004). Overcoming the effects of differential skewness of test items in scale construction. SA Journal of Industrial Psychology, 30 (4), 27-43.

Schepers, J.M. \& Gropp, L. (2005). The factor structure, metrical properties, and convergent validity of the third edition (1999) of the Locus of Control Inventory. SA Journal of Industrial Psychology, (in press).

Tabachnick, B.G. \& Fidell, L.S. (1983). Using multivariate statistics. New York: Harper \& Row. 